\title{
The Effect of Phenoxymethyl Side Groups on the Liquid Crystal Alignment Behavior of Polystyrene Derivatives
}

\author{
Hyo Kang and Jong-Chan Lee* \\ Department of Chemical and Biological Engineering, Seoul National University, Seoul 151-742, Korea \\ Daeseung Kang \\ Department of Electrical Engineering, Soongsil University, Seoul 156-743, Korea
}

Received October 14, 2008; Revised December 2, 2008; Accepted December 3, 2008

\begin{abstract}
We synthesized a series of polystyrene derivatives containing various side chain terminal moieties, such as phenoxymethyl, 4-methoxyphenoxymethyl, 4-fluorophenoxymethyl, 4-methylphenoxymethyl, and 4-trifluoromethoxyphenoxymethyl groups, using polymer analogous reactions, in order to investigate the effect of the side group on their liquid crystal (LC) alignment behaviors. The polymers containing 4-fluorophenoxymethyl, 4-methylphenoxymethyl, or 4-trifluoromethoxyphenoxymethyl side groups had lower surface energy values and the LC cells fabricated using the unrubbed films of these polymers showed homeotropic LC alignment behavior. The LC cells fabricated using the rubbed films of the polymers containing phenoxymethyl or 4-fluorophenoxymethyl groups showed homogeneous planar LC alignment behavior in which the LCs were aligned perpendicular to the rubbing direction. This homogeneous planar and perpendicular alignment behavior was ascribed to the favorable anisotropic interactions between the LC molecules and the side groups preferentially oriented perpendicular to the rubbing direction.
\end{abstract}

Keywords: liquid crystal, alignment, polystyrene.

\section{Introduction}

Liquid crystal (LC) alignment behavior on polymer substrates has been studied very widely due to the practical applications in the liquid crystal display (LCD) industry. ${ }^{1-6}$ The mechanical rubbing of polyimide (PI) surfaces is the most commonly used technique for producing LC alignment layers, ${ }^{7-21}$ which can induce stable homogeneous planar LC alignment ${ }^{19,20}$ or homeotropic LC alignment. ${ }^{14,18}$ The LC alignment properties such as the pretilt angle and electro-optical (E-O) performance on polyimide surfaces are known to be affected by the molecular structure of the polyimide such as the flexibility of the polymer backbone, isomeric structure of the mesogen end groups, spacer length, and spacer conformation in the side chains. ${ }^{22}$ For example, the pretilt angle of the LCs on polyimide surfaces with rigid aromatic side groups is $0.6^{\circ}$, while that of the LCs on polyimide surfaces with flexible alkyl side groups is high above $89.6^{\circ} .^{23}$ The different E-O properties of the LC cells made from polyimides having flexible $n$-alkyl side groups and fluorinated side groups were also reported. ${ }^{24}$

The mechanical rubbing of polystyrene (PS) surfaces can

*Corresponding Author. E-mail: jongchan@snu.ac.kr also produce homogeneous planar LC alignment layers, where the LC molecules are aligned perpendicular to the rubbing direction. ${ }^{25-33}$ However, this perpendicular LC alignment produces a very low pretilt angle of about $0^{026,31}$ as well as a weak azimuthal anchoring energy of less than $10^{-7}-10^{-8} \mathrm{~J} / \mathrm{m}^{2},{ }^{31-33}$ which is too low to produce a stable LC cell for practical applications in LCD devices. The homogeneity of an LC cell fabricated with the rubbed PS film is lost after 1 day. ${ }^{31-33}$ Recently, we found that the rubbed films of polystyrene derivatives containing coumarin side groups can produce very stable LC alignment layers having a high azimuthal anchoring energy of about $7 \times 10^{-5} \mathrm{~J} / \mathrm{m}^{2}$ and the LC cells made from the rubbed films of these polymers maintain their LC aligning ability at elevated temperatures of about $150{ }^{\circ} \mathrm{C} .{ }^{34}$ These LC cells show good E-O properties similar to those of LC cells prepared from rubbed commercial polyimide films. ${ }^{35} \mathrm{We}$ also found that the LC cell fabricated with the unrubbed film of 2-naphthoxymethylsubstituted polystyrene exhibited homeotropic LC alignment behavior with a high pretilt angle of approximately $90^{\circ} .{ }^{36}$ In these cases, the additional phenyl groups in the side chain of polystyrene were found to be the key factor in improving the LC alignment properties and inducing stable alignment behavior through increased $\pi$ - $\pi$ interactions and 
steric effects.

In this study we synthesized a series of polystyrenes having various additional phenoxymethyl side groups (Figure 1) in order to further understand the LC alignment behavior of the polystyrene derivatives. The synthesis and characterization of these polymers and the optical properties of the LC cells fabricated with the unrubbed or rubbed polymer films are investigated in this paper.

\section{Experimental}

Materials. Phenol, 4-fluorophenol, 4-methoxyphenol, 4methylphenol, 4-trifluoromethoxyphenol, 4-chloromethylstyrene, and potassium carbonate were purchased from Aldrich Chemical Co. and nematic LC (5CB) was purchased from Merck Co. $N, N^{\prime}$-Dimethylacetamide (DMAc) was dried over molecular sieves (4 $\AA$ ). Tetrahydrofuran (THF) was dried by refluxing it with benzophenone and sodium followed by distillation. 4-Chloromethylstyrene (Aldrich) was purified by column chromatography on silica gel using $n$-hexane as the eluent to remove any impurities and inhibitors such as tert-butylcatechol and nitroparaffin. 2,2'-Azobisisobutyronitrile (AIBN, Junsei Chemical Co. Ltd.) was used as an initiator. AIBN was purified by recrystallization using methanol. Poly(chloromethylstyrene) (PCMS of $M_{n}$ $=18,500$ and $M_{w} / M_{n}=2.40$ and $T_{g}=106{ }^{\circ} \mathrm{C}$ ) and polystyrene (PS of $M_{n}=37,000$ and $M_{w} / M_{n}=2.02$ and $T_{g}=104{ }^{\circ} \mathrm{C}$ ) were obtained through the conventional free radical polymerization of 4-chloromethylstyrene (10.0 g, $65.8 \mathrm{mmol})$ and styrene (2.0 g, $19.2 \mathrm{mmol})$ using AIBN (2.0 wt\% based on monomer) in dried THF $(20 \mathrm{~mL})$ under a nitrogen atmosphere, respectively. ${ }^{37}$ All other reagents and solvents were used as received.

Preparation of Phenoxymethyl-Substituted Polystyrene (PHP). A mixture of phenol (0.56 g, $5.92 \mathrm{mmol}, 180 \mathrm{~mol} \%$ compared with PCMS) and potassium carbonate $(0.91 \mathrm{~g}$, $6.58 \mathrm{mmol}, 200 \mathrm{~mol} \%$ compared with PCMS) in $N, N^{\prime}$-dimethylacetamide (DMAc, $10 \mathrm{~mL}$ ) was heated to $80^{\circ} \mathrm{C}$. PCMS $(0.5 \mathrm{~g}, 3.29 \mathrm{mmol})$ solution in DMAc $(10 \mathrm{~mL})$ was added to the mixture and then magnetically stirred at $80{ }^{\circ} \mathrm{C}$ for $12 \mathrm{~h}$ under a nitrogen atmosphere. The solution mixture was cooled to room temperature and then poured into methanol to obtain a white precipitate. The precipitate was further purified by several reprecipitations from DMAc solution into methanol and then washed with water to remove any potassium carbonate and remaining salts. The product was obtained in a yield of above $80 \%$ after dried under a vacuum overnight.

The degree (\%) of substitution was calculated by comparing the multiplet at $6.2-7.0 \mathrm{ppm}(5 \mathrm{H})$ with the backbone peak at 1.0-2.3 ppm $(3 \mathrm{H})$, which included the contribution of the residual poly(chloromethylstyrene) and found to be about $100 \%$.

${ }^{1} \mathrm{H}$ NMR $\left(\mathrm{CDCl}_{3}\right): \delta=1.0-1.5$ (m, 2H, $\left.-\mathrm{CH}_{2}-\mathrm{CH}-\mathrm{Ph}-\right), 1.6-2.3$ (m, 1H, - $\mathrm{CH}_{2}-\mathrm{CH}$-Ph-), 4.7-5.1 (s, 2H, -Ph-CH $\mathrm{CH}_{2}-\mathrm{O}-$ ), 6.2-6.8 (m, $2 \mathrm{H},-\mathrm{CH}_{2}-\mathrm{O}-\mathrm{Ph} H$ ), 6.8-7.0 (m, 3H, $-\mathrm{CH}_{2}-\mathrm{O}-\mathrm{Ph} H$ ), 7.0-7.2 (m, 2H, -CH-PhH-CH$-\mathrm{O}-$ ), 7.2-7.4 (m, 2H, -CH-PhH-CH

IR (KBr): 2923 (asymmetric aliphatic C-H stretching), 2856 (symmetric aliphatic $\mathrm{C}-\mathrm{H}$ stretching), 1607 (ring $\mathrm{C}=\mathrm{C}$ stretching), 1508 (ring $\mathrm{C}=\mathrm{C}$ stretching of the phenyloxy unit).

Preparation of 4-Methoxyphenoxymethyl-Substituted Polystyrene (P4MOP). P4MOP was synthesized using the same procedure as that used for the preparation of PHP, except that 4-methoxyphenol (0.73 g, $5.92 \mathrm{mmol}, 180 \mathrm{~mol} \%$ compared with PCMS) was used instead of phenol. The product was obtained in a yield of above $75 \%$.

The degree (\%) of substitution was calculated by comparing the singlet at 3.6-3.8 ppm $(3 \mathrm{H})$ with the backbone peak at $1.0-2.3 \mathrm{ppm}(3 \mathrm{H})$ which included the contribution of the residual poly(chloromethylstyrene) and found to be about $100 \%$.

${ }^{1} \mathrm{H}$ NMR $\left(\mathrm{CDCl}_{3}\right): \delta=1.0-2.3\left(\mathrm{~m}, 3 \mathrm{H},-\mathrm{CH}_{2}-\mathrm{CH}-\mathrm{Ph}\right), 3.6-$ 3.8 (s, 3H, -O-Ph-OCH $H_{3}$, 4.6-5.0 (s, 2H, Ph-CH $\left.\mathrm{H}_{2}-\mathrm{O}-\right)$, 6.1-6.7 (m, 4H, -O-PhH-OCH 3 ), 6.7-7.2 (m, 4H, -CH-PhH- $\mathrm{CH}_{2}$ ).

IR (KBr): 2923 (asymmetric aliphatic C-H stretching), 2856 (symmetric aliphatic $\mathrm{C}-\mathrm{H}$ stretching), 1607 (ring $\mathrm{C}=\mathrm{C}$ stretching), 1508 (ring $\mathrm{C}=\mathrm{C}$ stretching of the phenyloxy unit).

Preparation of 4-Fluorophenoxymethyl-Substituted Polystyrene (P4FP). P4FP was synthesized using the same procedure as that used for the preparation of PHP, except that 4-fluorophenol $(0.664 \mathrm{~g}, 5.92 \mathrm{mmol}, 180 \mathrm{~mol} \% \mathrm{com}-$ pared with PCMS) was used instead of phenol. The product was obtained in a yield of above $80 \%$.

The degree (\%) of substitution was calculated by comparing the multiplet at $6.1-7.1 \mathrm{ppm}(4 \mathrm{H})$ with the backbone peak at 0.8-2.3 ppm (3H) which included the contribution of the residual poly(chloromethylstyrene) and found to be about $100 \%$.

Other 4-fluorophenoxymethyl-substituted polystyrenes having different degree of substitution (P4FP\#) were synthesized using the same procedure as that used for the preparation of P4FP except for the amount of 4-fluorophenol in the reaction. For example, P4FP80, P4FP60, P4FP40, and P4FP20, where the numbers indicate the mole percent of 4-fluorophenoxy containing monomeric units in the polymer, were prepared with 4-fluorophenol of $0.29 \mathrm{~g}(2.63 \mathrm{mmol}), 0.22 \mathrm{~g}$ (1.97 mmol), $0.15 \mathrm{~g}(1.32 \mathrm{mmol})$, and $0.07 \mathrm{~g}(0.66 \mathrm{mmol})$, respectively, with potassium carbonate of $0.91 \mathrm{~g}(6.58$ mmol, $200 \mathrm{~mol} \mathrm{\% ).}$

${ }^{1} \mathrm{H}$ NMR $\left(\mathrm{CDCl}_{3}\right): \delta=0.8-2.3\left(\mathrm{~m}, 3 \mathrm{H},-\mathrm{CH}_{2}-\mathrm{CH}-\mathrm{Ph}\right), 4.6-$ 5.1 (s, 2H, Ph-CH2-O-), 6.1-6.7 (m, 2H, -O-PhH-F), 6.7-7.1 (m, 2H, -O-PhH-F), 7.1-7.4 (m, 4H, -CH- $\mathrm{PhH}-\mathrm{CH}_{2}-$ ).

IR (KBr): 2923 (asymmetric aliphatic C-H stretching), 2856 (symmetric aliphatic $\mathrm{C}-\mathrm{H}$ stretching), 1607 (ring $\mathrm{C}=\mathrm{C}$ stretching), 1508 (ring $\mathrm{C}=\mathrm{C}$ stretching of the phenyloxy unit), 1198 (stretching vibrational mode of aromatic C-F).

Preparation of 4-Methylphenoxymethyl-Substitued Polystyrene (P4MP). P4MP was synthesized using the 
same procedure as that used for the preparation of PHP, except that 4-methylphenol (0.64 g, $5.92 \mathrm{mmol}, 180 \mathrm{~mol} \%$ compared with PCMS) was used instead of phenol. The product was obtained in above $75 \%$ yield after drying overnight in a vacuum.

The degree (\%) of substitution was calculated by comparing the singlet at 2.1-2.4 ppm $(3 \mathrm{H})$ with the backbone peak at 1.0-2.1 ppm $(3 \mathrm{H})$ which included the contribution of the residual poly(chloromethylstyrene) and found to be about $100 \%$.

Other 4-methylphenoxymethyl-substitued polystyrenes having different degree of substitution (P4MP\#) were synthesized using the same procedure as that used for the preparation of P4MP except for the amount of 4-methylphenol in the reaction. For example, P4MP80, P4MP60, P4MP40, and P4MP20, where the numbers indicate the mole percent of 4-methylphenoxy containing monomeric units in the polymer, were prepared with 4-methylphenol of $0.28 \mathrm{~g}(2.63 \mathrm{mmol})$, $0.21 \mathrm{~g}(1.97 \mathrm{mmol}), 0.14 \mathrm{~g}(1.32 \mathrm{mmol})$, and $0.07 \mathrm{~g}(0.66 \mathrm{mmol})$, respectively, with potassium carbonate of $0.91 \mathrm{~g}(6.58$ mmol, $200 \mathrm{~mol} \%)$.

${ }^{1} \mathrm{H} \mathrm{NMR}\left(\mathrm{CDCl}_{3}\right): \delta=1.0-1.5$ (m, 2H, $\left.-\mathrm{CH}_{2}-\mathrm{CH}-\mathrm{Ph}-\right), 1.6-2.1$ (m, $1 \mathrm{H},-\mathrm{CH}_{2}-\mathrm{CH}-\mathrm{Ph}-$ ), 2.1-2.4 (s, 3H, -O-Ph- $\mathrm{CH}_{3}$ ), 4.6-5.1 (s, 2H, -Ph-CH $\left.H_{2}-\mathrm{O}-\right)$, 6.1-6.6 (m, $2 \mathrm{H},-\mathrm{O}-\mathrm{Ph} H-\mathrm{CH}_{3}$ ), 6.6-6.9 (m, 2H, -O-PhH-CH${ }_{3}$ ), 6.9-7.2 (m, 4H, -CH-PhH-CH - -O-).

IR (KBr): 2923 (asymmetric aliphatic $\mathrm{C}-\mathrm{H}$ stretching in the vinyl backbone and 4-methylphenoxy side groups), 2856 (symmetric aliphatic $\mathrm{C}-\mathrm{H}$ stretching in the vinyl backbone and 4-methylphenoxy side groups), 1607 (ring $\mathrm{C}=\mathrm{C}$ stretching), 1508 (ring $\mathrm{C}=\mathrm{C}$ stretching of the phenyloxy unit).

Preparation of 4-Trifluoromethoxyphenoxymethyl-Substituted Polystyrene (PTFMOP). PTFMOP was synthesized using the same procedure as that used for the preparation of PHP, except that 4-trifluoromethoxyphenol $(1.05 \mathrm{~g}, 5.92 \mathrm{mmol}$, $180 \mathrm{~mol} \%$ compared with PCMS) was used instead of phenol. The product was obtained in a yield of above $75 \%$.

The degree (\%) of substitution was calculated by comparing the multiplet at $6.2-7.2 \mathrm{ppm}(4 \mathrm{H})$ with the backbone peak at 1.1-2.3 ppm $(3 \mathrm{H})$ which included the contribution of the residual poly(chloromethylstyrene) and found to be about $100 \%$.

Other 4-trifluoromethoxyphenoxymethyl-substituted polystyrenes having different degree of substitution (PTFMOP\#) were synthesized using the same procedure as that used for the preparation of PTFMOP except for the amount of 4-trifluoromethoxyphenol in the reaction. For example, PTFMOP80, PTFMOP60, PTFMOP40, and PTFMOP20, where the numbers indicate the mole percent of 4-trifluoromethoxyphenoxy containing monomeric units in the polymer, were prepared with 4-trifluoromethoxyphenol of $0.47 \mathrm{~g}(2.63 \mathrm{mmol}), 0.35 \mathrm{~g}$ $(1.97 \mathrm{mmol}), 0.23 \mathrm{~g}(1.32 \mathrm{mmol})$, and $0.12 \mathrm{~g}(0.66 \mathrm{mmol})$, respectively, with potassium carbonate of $0.91 \mathrm{~g}(6.58 \mathrm{mmol}$, $200 \mathrm{~mol} \%$ ).

${ }^{1} \mathrm{H}$ NMR $\left(\mathrm{CDCl}_{3}\right): \delta=1.1-2.3\left(\mathrm{~m}, 3 \mathrm{H},-\mathrm{CH}_{2}-\mathrm{CH}-\mathrm{Ph}\right), 4.7-5.0$ (s, 2H, Ph-CH $\mathrm{CH}_{2}-\mathrm{O}-$ ), 6.2-7.2 (m, 4H, -O-PhH-OCF 3 ), 6.9-7.2 (m, 4H, -CH- $\mathrm{Ph} H-\mathrm{CH}_{2}-$ ).

IR (KBr): 2923 (asymmetric aliphatic C-H stretching), 2856 (symmetric aliphatic $\mathrm{C}-\mathrm{H}$ stretching), 1607 (ring $\mathrm{C}=\mathrm{C}$ stretching), 1508 (ring $\mathrm{C}=\mathrm{C}$ stretching of the phenyloxy unit), 1245 (stretching vibrational mode of $\mathrm{CF}_{3}$ ).

Film Preparation and LC Alignment Process. Solutions of PHP, P4FP, P4FP\#, P4MP, P4MP\#, PTFMOP, and PTFMOP\# in toluene (2 wt $\%$ ) and $\mathrm{P} 4 \mathrm{MOP}$ in $\mathrm{CHCl}_{3}(2$ wt $\%)$ were prepared. These solutions were filtered using a PTFE membrane with a pore size of $0.45 \mu \mathrm{m}$. Thin films of the polymers were prepared by spin-coating $(2,000 \mathrm{rpm}, 30$ $\mathrm{sec}$ ) them onto $1.5 \mathrm{~cm} \times 1.5 \mathrm{~cm}$ ITO coated glass substrates. The polymer films were rubbed using a rubbing machine (RMS-50-M, Nam Il Optical Components Corp.). The rubbing density equation is written as $L / l=N[(2 \pi r n / 60 v)-1]$, where $L$ is the total length of the rubbing cloth $(\mathrm{mm}), l$ is the contact length of the circumference of the rubbing roller (mm), $N$ is the cumulative number of rubbings, $n$ is the speed (rpm) of the rubbing roller, $r$ is the radius $(\mathrm{cm})$ of the rubbing roller, and $v$ is the velocity $(\mathrm{cm} / \mathrm{s})$ of the substrate stage. $^{17,20}$

LC Cell Assembly. Twisted nematic (TN) and antiparallel LC cells were fabricated using the unrubbed or rubbed polymer films onto ITO coated glass slides. The TN LC cells were made by assembling the films together orthogonally with respect to the rubbing direction for the unrubbed or rubbed films using spacers with a thickness of $6.5 \mu \mathrm{m}$. The antiparallel LC cells were constructed by assembling the films together antiparallel with respect to the rubbing direction using spacers with thicknesses of 50 and $6.5 \mu \mathrm{m}$. The LC cells were filled with a nematic LC (5CB) (Merck Co., $n_{e}=1.736, n_{o}=1.5442$, and $\Delta \varepsilon=14.5$, where $n_{e}, n_{o}$, and $\Delta \varepsilon$ represent the extraordinary refractive index, ordinary refractive index, and dielectric anisotropy, respectively), in an isotropic state to avoid creating flow alignment through capillary action, and were then sealed with epoxy.

Instrumentation. The ${ }^{1} \mathrm{H}$ NMR measurements were carried out on a Bruker AVANCE spectrometer at $300 \mathrm{MHz}$. The FTIR spectra were recorded at a resolution of $4 \mathrm{~cm}^{-1}$ and the interferograms were accumulated 32 times. Gel permeation chromatography (GPC) was used to measure the number average molecular weight $\left(M_{n}\right)$ and polydispersity index $\left(M_{w} / M_{n}\right)$ of the synthesized polymer with respect to polystyrene standards using tetrahydrofuran (THF) as the eluent and a UV detector. Differential scanning calorimetry (DSC) measurements were carried out on a TA instruments 2920 at a heating and cooling rate of $20^{\circ} \mathrm{C} / \mathrm{min}$ under a nitrogen atmosphere. Thermal gravimetric analysis (TGA-2050, TA instrument) was used to investigate the thermal stability of the polymer samples. The samples were heated from room temperature to $800^{\circ} \mathrm{C}$ at a heating rate of $10^{\circ} \mathrm{C} / \mathrm{min}$ under a nitrogen atmosphere. The polarized FTIR measurements of the rubbed polymer films with a rubbing density of 
100 were carried out using a Perkin Elmer Spectrum 2000 spectrometer equipped with a polarizer. The polymer films used for the FTIR measurements were prepared by spin coating (1,000 rpm, $30 \mathrm{sec}) 3 \mathrm{wt} \%$ PHP, P4FP, P4MP, and PTFMOP solutions in toluene and a $3 \mathrm{wt} \% \mathrm{P} 4 \mathrm{MOP}$ solution in $\mathrm{CHCl}_{3}$ onto a silicon wafer. The contact angles of distilled water and methylene iodide on the polymer films were determined with a Kruss DSA10 contact angle analyzer equipped with drop shape analysis software. The OwensWendt's equation was applied to calculate the surface energy values from the contact angles. ${ }^{38}$ The $\mathrm{LC}$ alignment direction of the antiparallel LC cells was investigated by measuring the angular dependence of the absorbance of a dichroic dye (disperse blue 1) dissolved in 5CB at a concentration of $1 \mathrm{wt} \%$ on the rotation angle of the samples using optical apparatus equipped with a He-Ne laser, a polarizer, and a photodiode detector. ${ }^{20}$ The pretilt angle of the antiparallel LC cells was measured by the crystal rotation method. ${ }^{39}$ The cell gap was measured before filling the LCs using a spectrophotometer (Ocean Optics Inc., S 2000). The polarized optical microscopy (POM) images of the LC cell were taken using an optical microscopy (Nikon, ECLIPSE E600 POL) equipped with a polarizer and digital camera (Nikon, COOLPIX995).

\section{Results and Discussion}

Figure 1 shows the synthetic routes to the phenoxymethyl-substituted polystyrene (PHP, P4MOP, P4FP, P4MP, and PTFMOP) and copolymers of P4FP, P4MP, and PTFMOP (P4FP\#, P4MP\#, and PTFMOP\#, where \# is the molar content (\%) of 4-fluorophenoxymethyl, 4-methylphenoxymethyl, and 4-trifluoromethoxyphenoxymethyl side groups). The average molecular weights $\left(M_{n}\right)$ of these polymer series synthesized from the PCMS $\left(M_{n}=18,500\right)$ were always larger than 19,300 indicating that polymer modification from PCMS to the polymers in this paper gave rise to increase of average molecular weights of polymers, as expected (Table I).

The thermal properties of these polymers were examined using DSC and TGA (Figures 2 and 3, Table I). All of the polymers were found to be amorphous because only one glass transition temperatures $\left(T_{g}\right)$ was observed in their DSC

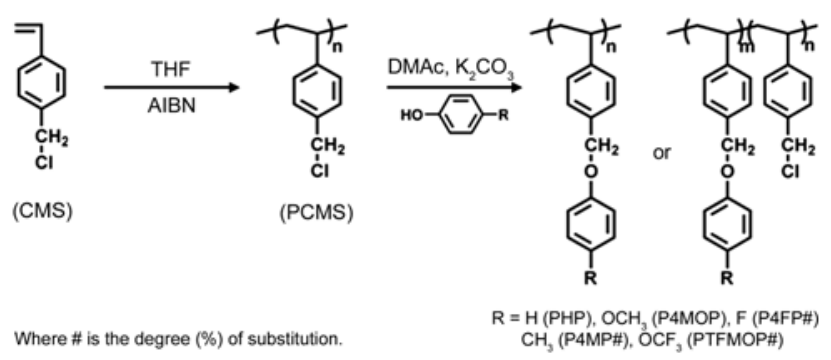

Figure 1. Synthetic routes to the polymers.
Table I. Results of the Characterization of the Polymers Using ${ }^{1} \mathrm{H}$ NMR, GPC, DSC, and TGA

\begin{tabular}{|c|c|c|c|c|c|}
\hline $\begin{array}{l}\text { Polymer } \\
\text { Designation }\end{array}$ & $\begin{array}{c}\text { Degree of } \\
\text { Substitution (\%) }\end{array}$ & $M_{n}^{a}$ & $M_{w} / M_{n}^{a}$ & $\begin{array}{c}T_{g} \\
\left({ }^{\circ} \mathrm{C}\right)\end{array}$ & $\begin{array}{l}T_{d, 90 \%} \\
\left({ }^{\circ} \mathrm{C}\right)^{b}\end{array}$ \\
\hline PS & & 37,000 & 2.02 & 104 & 363 \\
\hline PCMS & & 18,500 & 2.40 & 106 & 308 \\
\hline PHP & $\sim 100$ & 21,700 & 2.25 & 71 & 342 \\
\hline P4MOP & $\sim 100$ & 22,900 & 2.56 & 63 & 323 \\
\hline P4FP & $\sim 100$ & 24,000 & 2.40 & 58 & 346 \\
\hline P4FP80 & $\sim 80$ & 22,900 & 2.35 & 68 & 332 \\
\hline P4FP60 & $\sim 60$ & 21,700 & 2.22 & 80 & 321 \\
\hline P4FP40 & $\sim 40$ & 20,500 & 2.28 & 83 & 312 \\
\hline P4FP20 & $\sim 20$ & 19,500 & 2.37 & 96 & 297 \\
\hline P4MP & $\sim 100$ & 22,600 & 3.00 & 67 & 352 \\
\hline P4MP80 & $\sim 80$ & 22,200 & 2.53 & 67 & 330 \\
\hline P4MP60 & $\sim 60$ & 21,500 & 2.48 & 79 & 323 \\
\hline P4MP40 & $\sim 40$ & 20,500 & 2.65 & 81 & 322 \\
\hline P4MP20 & $\sim 20$ & 19,300 & 2.20 & 99 & 325 \\
\hline PTFMOP & $\sim 100$ & 30,500 & 2.61 & 53 & 356 \\
\hline PTFMOP80 & $\sim 80$ & 29,300 & 2.65 & 67 & 329 \\
\hline PTFMOP60 & $\sim 60$ & 27,600 & 2.53 & 79 & 330 \\
\hline PTFMOP40 & $\sim 40$ & 25,100 & 2.44 & 81 & 332 \\
\hline PTFMOP20 & $\sim 20$ & 22,200 & 2.62 & 96 & 335 \\
\hline
\end{tabular}

${ }^{a}$ Obtained from GPC using THF as solvent with respect to monodisperse polystyrene as standards. ${ }^{b}$ The decomposition temperature $\left(T_{d, 90 \%}\right)$ is defined as 10 weight percent loss.

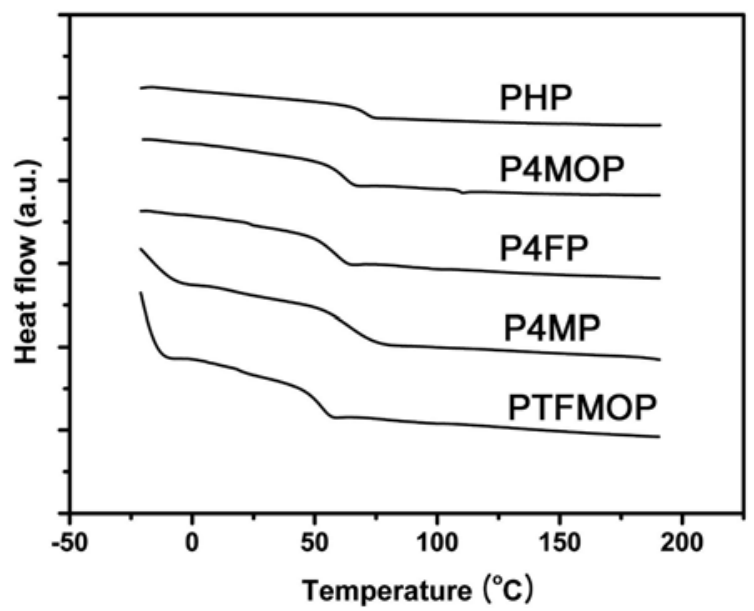

Figure 2. DSC thermograms of the polymers.

thermograms (Figure 2). The $T_{g}$ values of the polystyrene derivatives newly synthesized in this work, all of which have identical backbone structures, were found to be always lower than those of PS and PCMS. The decrease of $T_{g}$ of 


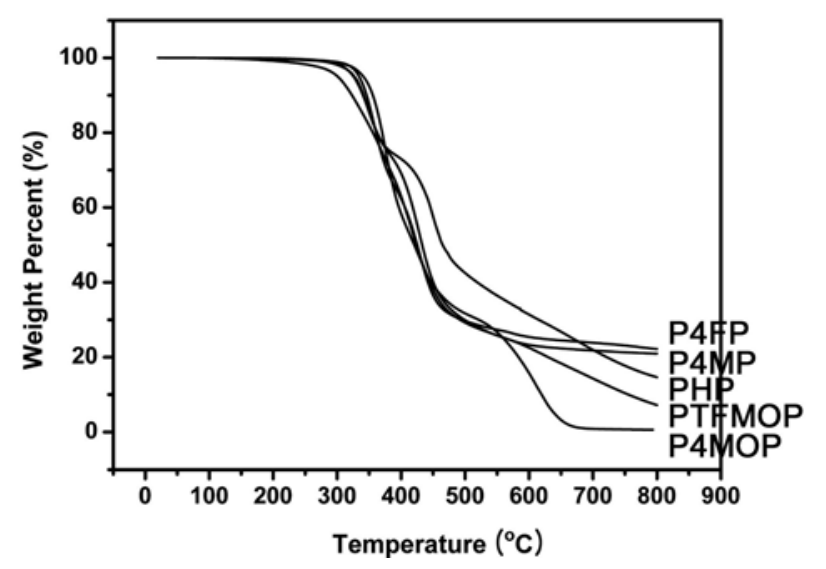

Figure 3. TGA curves of the polymers.

polystyrene derivatives having bulky substituents in the side chain was reported before; for example, the $T_{g}$ 's of the poly (4-phenoxystyrene), poly(4-p-toluoylstyrene), and 2-naphthoxymethyl-substituted polystyrene are lower than that of polystyrene. ${ }^{36,40}$ The lower $T_{g}$ values of polymers having bulky side groups have been ascribed to the increase of the free volume in the polymer. ${ }^{41-43}$ For the same reason as the molar content of the bulky side group increases, the $T_{g}$ of the polymers decreases (Table I).

The thermal decomposition temperatures $\left(T_{d, 90 \%}\right)$ of the polystyrene derivatives were also found to be lower than that of polystyrene (Figure 3 and Table I). The lower decomposition temperature of the polystyrene derivatives could be ascribed to the incorporation of an oxymethyl group having a lower activation energy of thermal decomposition. ${ }^{44}$ Overall, the incorporation of the various phenoxymethyl side groups into the polystyrene decreases the glass transition and thermal decomposition temperatures of the polymers.

At first the LC alignment behavior of the LC cells fabricated with the unrubbed films of the homopolymers was investigated. Random planar LC alignment was observed for the LC cells fabricated using the unrubbed films of PS, PHP, and P4MOP and homeotropic LC alignment was observed for those fabricated from the unrubbed films of 4MP, P4FP, and PTFMOP. The polarized optical microscopy (POM) images of the LC cells fabricated with the unrubbed films of the copolymers of P4MP, P4FP, and PTFMOP, which show homeotropic LC alignment, were observed, in order to investigate the effect of the amount of phenoxymethyl side groups on the LC alignment property. Figure 4 shows the dark and conoscopic POM images of the LC cells made from these copolymers. The LC cells fabricated with the P4FP\# and P4MP\# films having side group content of less than about $40 \mathrm{~mol} \%$ (P4FP20, P4FP40, P4MP20, and P4MP40) show LC textures with birefringence in the dark images, while homeotropic LC alignment behavior was observed for the LC cells fabricated with the
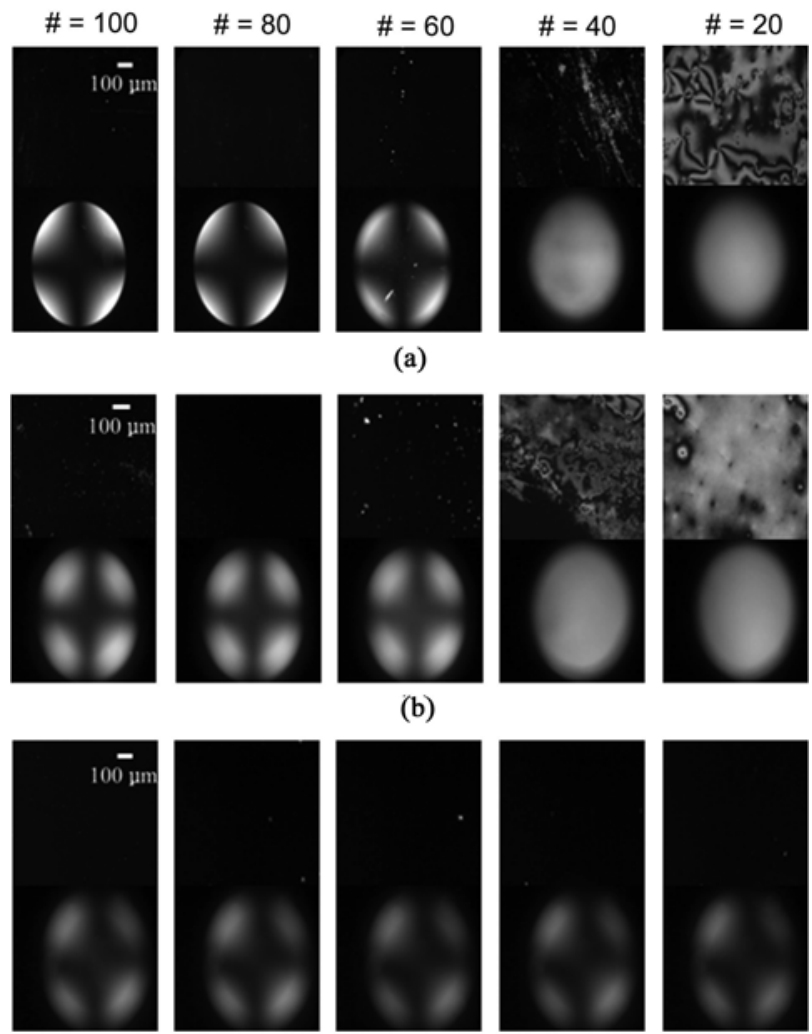

(c)

Figure 4. Dark and conoscopic polarized optical microscopy (POM) images of the LC cells made from (a) P4FP\#, (b) P4MP\#, and (c) PTFMOP\# films according to the molar contents of the side functional groups in the polymer (\# = the contents $(\%)$ of the side functional groups).

polymer films having phenoxymethyl side group content larger than about $60 \mathrm{~mol} \%$ (P4FP60, P4FP80, P4FP, P4MP60, P4MP80, and P4MP). On the contrary, all of the LC cells made from the unrubbed films of PTFMOP\# films showed homeotropic LC alignment behavior, indicating that only a small amount of 4-trifluoromethoxy groups in the phenoxymethyl-substituted polystyrene can produce homeotropic alignment. Therefore, the homeotropic LC aligning ability of the type of phenoxymethyl side groups increases in the order of 4-phenoxymethyl $\cong 4$-methoxyphenoxymethyl $<$ 4-fluorophenoxymethyl $\cong 4$-methylphenoxymethyl $<$ 4-trifluoromethoxyphenoxymethyl side groups. This order was found to be related to the surface energy values of the polymer films discussed later in this paper.

The LC alignment behavior on the rubbed polymers, such as the aligning ability and alignment direction, was investigated by observing the POM images of the twisted nematic (TN) LC cells. Figure 5 shows the dark and conoscopic (inlet) POM images for the LC cells made from the rubbed polymer films with a rubbing density of 100 . The LC cells made from the PHP and P4FP films show homogeneous 


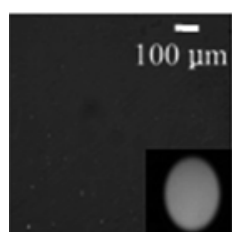

(a)

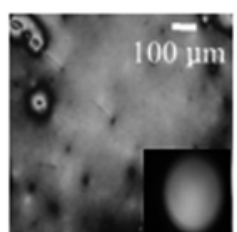

(b)

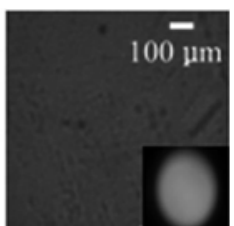

(c)

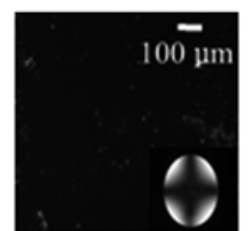

(d)

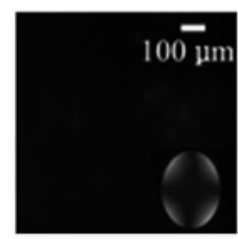

(e)
Figure 5. Dark and conoscopic polarized optical microscopy (POM) images (inlet) of the LC cells made from rubbed polymer ((a) PHP, (b) P4MOP, (c) P4FP, (d) P4MP, and (e) PTFMOP) films with a rubbing density of 100 .

planar LC alignment behavior, as shown in Figures 5(a) and 5(c), respectively. However, the homogeneity of these LC cells was lost after a few days, indicating that the LC align-

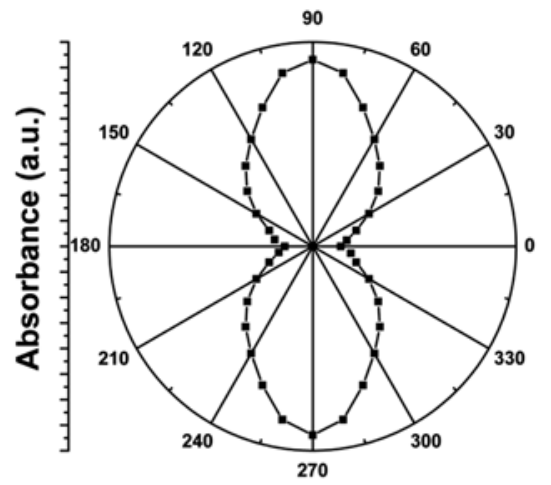

(a)

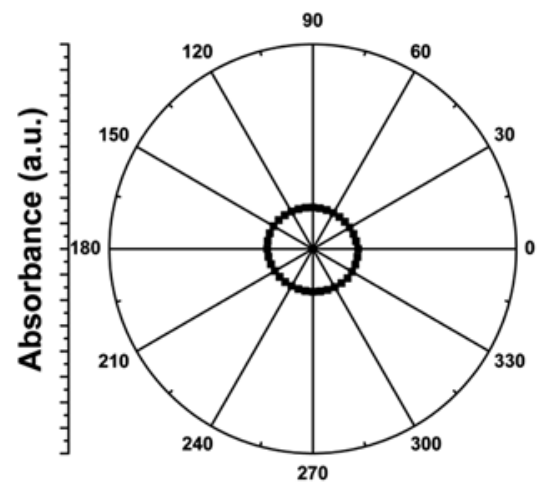

(c) ment ability of these films is not good similar to that of rubbed polystyrene. Figure 5(b) shows that the rubbed P4MOP film induces only random planar LC alignment. The LC cells fabricated with the rubbed P4MP and PTFMOP films show homeotropic LC alignment behavior (Figures 5(d) and (e)). This homeotropic alignment of the LC cells made from the rubbed P4MP and PTFMOP films was maintained for more than 12 months after the first LC cell was made.

The LC alignment direction of the LC molecules on the rubbed surface was further studied by measuring the polar diagrams of the absorbance of a dichroic dye (disperse blue 1) in the LC cells fabricated using the rubbed polymer films with a rubbing density of 100 (Figure 6). The rubbed PHP and P4FP films also show maximum absorbances along the $90^{\circ} \leftrightarrow 270^{\circ}$ directions, which are perpendicular with respect to the rubbing direction (Figures 6(a) and (b)). The polarized FTIR studies (discussed in the next paragraph) showed that the aromatic side groups on the rubbed surfaces of the PHP and P4FP films are oriented perpendicular with respect to the rubbing direction. The polar diagrams of the LC cells fabricated with the rubbed P4MP and PTFMOP films (Fig-

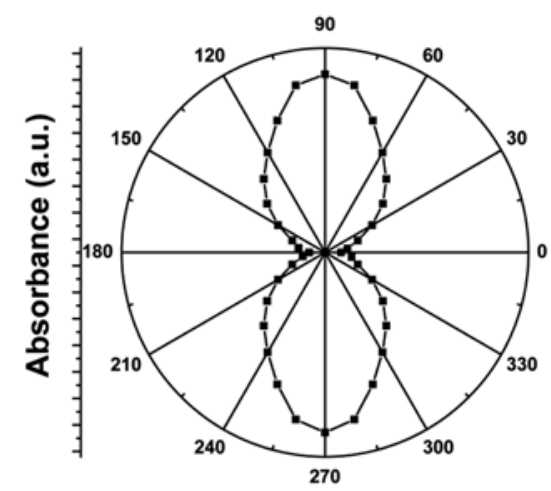

(b)

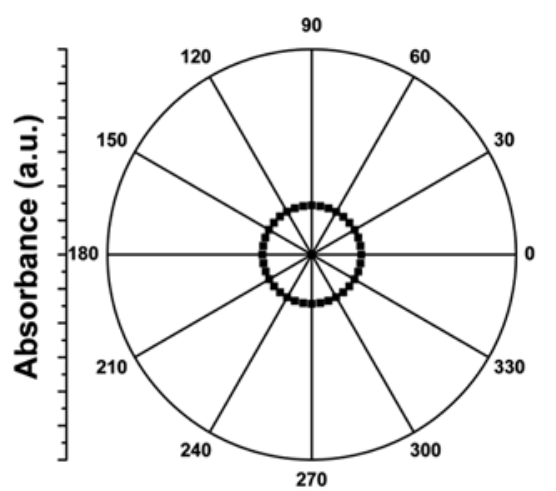

(d)

Rubbing direction

Figure 6. Polar diagrams of the absorbance of the dichroic dye (disperse blue 1) in antiparallel LC cells made from rubbed (a) PHP, (b) P4FP, (c) P4MP, and (d) PTFMOP films with a rubbing density of 100 as a function of rotation angle of the samples. 
Table II. The LC Alignment Behavior of the LC Cells Made from Unrubbed or Rubbed Polymer Films

\begin{tabular}{ccc}
\hline \multirow{2}{*}{$\begin{array}{c}\text { Polymer } \\
\text { Designation }\end{array}$} & \multicolumn{2}{c}{ LC Alignment Behavior } \\
\cline { 2 - 3 } & Before Rubbing & After Rubbing \\
\hline PHP & Random planar & Homogeneous planar \\
P4MOP & Random planar & Random planar \\
P4FP & Homeotropic & Homogeneous planar \\
P4MP & Homeotropic & Homeotropic \\
PTFMOP & Homeotropic & Homeotropic \\
\hline
\end{tabular}

${ }^{a}$ The LC cells made from rubbed polymer films with a rubbing density of 100 .

ures 6(c) and (d)) also show very good homeotropic LC alignment. Any good polar diagrams showing good orientation of LCs on the rubbed P4MOP film could not be measured due to the poor LC alignment. The LC alignment behavior of the LC cells is summarized in Table II.

Polarized FTIR studies were performed to determine the orientation of the side groups with respect to the rubbing direction on the LC alignment behavior. ${ }^{1,1720,31-33,45-48}$ Figure 7 shows the IR spectra of the rubbed (a) PHP and (b) P4FP films with a rubbing density of 100 on a Si-wafer with the IR monitoring light parallel and perpendicular with respect to the rubbing direction; the $\mathrm{C}=\mathrm{C}\left(1508 \mathrm{~cm}^{-1}\right)$ peaks from the aromatic rings in the side chains are more intense when the polarization of the incident beam is perpendicular to the rubbing direction, indicating that the aromatic side groups are oriented more or less perpendicular with respect to the rubbing direction. Therefore, the perpendicular LC alignment on the rubbed PHP and P4FP films should be arisen from the possible the favorable anisotropic interactions between the LC molecules and the aromatic side groups oriented perpendicular with respect to the rubbing direction. The IR spectra (not shown here) of the unrubbed polymer films did not have such a dichroic aspect for polarized IR light. We could also not observe any angular dependence in the IR spectra of the rubbed P4MOP, P4MP, or PTFMOP films, which induce random planar or homeotropic LC alignment behaviors.

The pretilt angles of the antiparallel LC cells were measured in order to determine the effect of the rubbing density on the $\mathrm{LC}$ alignment direction (Figure 8). The pretilt angles of the LCs on the rubbed PS and PHP films with a rubbing density of $<50$ and on the unrubbed or rubbed P4MOP films could not be measured, due to their poor LC alignment. Pretilt angles of approximately $0^{\circ}$ on the rubbed PS and PHP films were obtained at a rubbing density of $>50$. In the case of the P4FP, P4MP, and PTFMOP films, pretilt angles of about $90^{\circ}$ were observed for the LC cells made from the unrubbed polymer films. As the rubbing density increases from 0 to 250 , the pretilt angle decreases from $90^{\circ}$ to $86^{\circ}$ and from $90^{\circ}$ to $87^{\circ}$ for the rubbed P4MP and PTF-

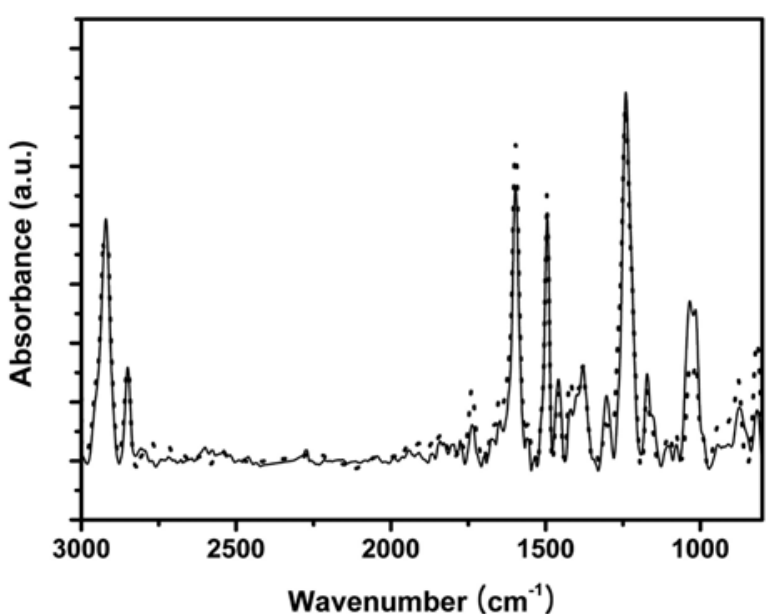

(a)

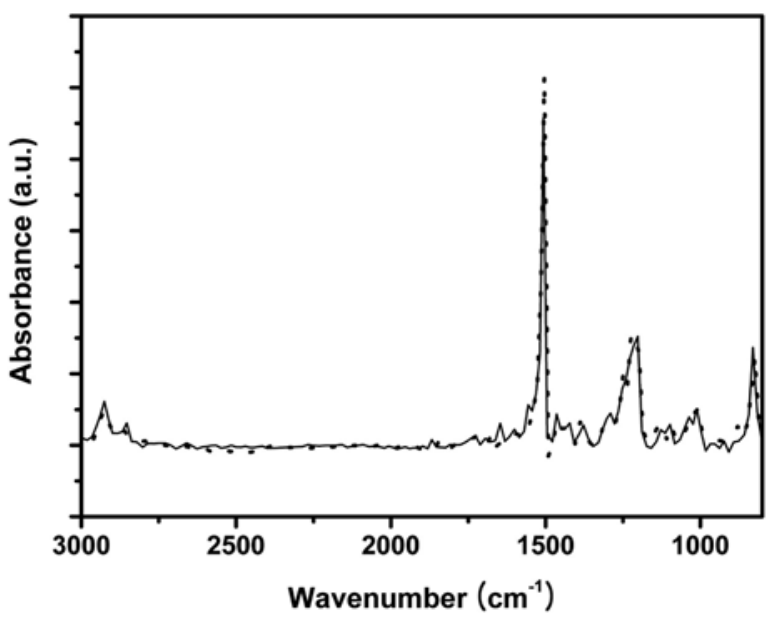

(b)

Figure 7. FTIR dichroic spectra of rubbed (a) PHP and (b) P4FP on Si-wafer film with a rubbing density of 100 . Solid and dotted line indicate the results obtained from the IR source parallel and perpendicular with respect to the rubbing direction, respectively.

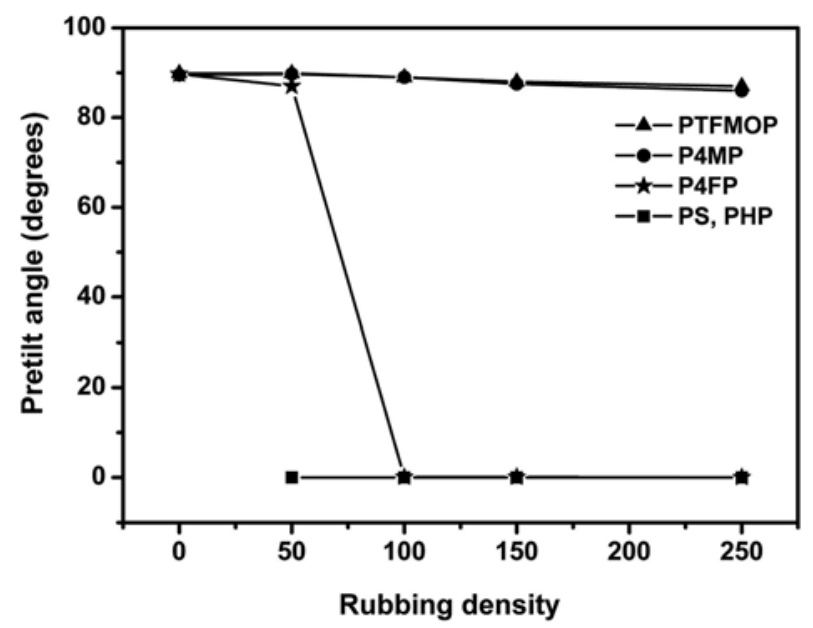

Figure 8. Pretilt angles of the LC cells fabricated with rubbed polymer films as a function of rubbing density. 
MOP films, respectively, indicating that their homeotropic alignment behaviors are still maintained. For the LC cell made from the rubbed P4FP film, as the rubbing density increases from 0 to 50 , the pretilt angle decreases gradually from $90^{\circ}$ to $87^{\circ}$, then decreases to about $0^{\circ}$ when the rubbing density increases above 100 , indicating that the LC alignment direction changes from homeotropic to homogeneous planar LC alignment.

It has been known that the high pretilt angles of LC molecules required to produce homeotropic alignment are related to the low surface energy values of the alignment layer and/ or the steric repulsions between the LC molecules and the alignment layers. ${ }^{36,49-56}$ Therefore, polyimides having long alkyl side groups have been widely used to align LCs perpendicular to the surface of the alignment layer, because the long alkyl groups can produce low surface energy layers due to their steric effect. ${ }^{51,56}$ We also found that the LC alignment behavior on the polystyrene derivatives in this study could be ascribed to the surface energy values. Table III lists the surface energy values of the polymer films based on the static contact angles of water and methylene iodide.

Table III. Surface Energy and Homeotropic LC Aligning Ability of Polymer Films

\begin{tabular}{ccccc}
\hline Polymer & \multicolumn{2}{c}{ Contact Angle $\left({ }^{\circ}\right)^{a}$} \\
\cline { 2 - 5 } Designation & Water & $\begin{array}{c}\text { Methylene } \\
\text { Iodide }\end{array}$ & $\begin{array}{c}\text { Surface Energy } \\
\left(\mathrm{mJ} / \mathrm{m}^{2}\right)^{b}\end{array}$ & $\begin{array}{c}\text { Homeotropic } \\
\text { LC Aligning } \\
\text { Ability }\end{array}$ \\
\hline PS & 82 & 28 & 45.54 & $\mathrm{X}$ \\
PCMS & 82 & 14 & 49.51 & $\mathrm{X}$ \\
PHP & 82 & 30 & 44.81 & $\mathrm{X}$ \\
P4MOP & 83 & 19 & 48.26 & $\mathrm{X}$ \\
P4FP & 82 & 36 & 42.44 & $\mathrm{O}$ \\
P4FP80 & 82 & 35 & 42.85 & $\mathrm{O}$ \\
P4FP60 & 82 & 34 & 43.25 & $\mathrm{O}$ \\
P4FP40 & 82 & 31 & 44.43 & $\mathrm{X}$ \\
P4FP20 & 82 & 21 & 47.80 & $\mathrm{X}$ \\
P4MP & 85 & 33 & 43.25 & $\mathrm{O}$ \\
P4MP80 & 85 & 32 & 43.66 & $\mathrm{O}$ \\
P4MP60 & 84 & 32 & 43.77 & $\mathrm{O}$ \\
P4MP40 & 83 & 28 & 45.41 & $\mathrm{X}$ \\
P4MP20 & 82 & 18 & 48.61 & $\mathrm{X}$ \\
PTFMOP & 94 & 68 & 25.14 & $\mathrm{O}$ \\
PTFMOP80 & 92 & 67 & 26.04 & $\mathrm{O}$ \\
PTFMOP60 & 90 & 65 & 27.42 & $\mathrm{O}$ \\
PTFMOP40 & 88 & 62 & 29.29 & $\mathrm{O}$ \\
PTFMOP20 & 82 & 57 & 33.26 & $\mathrm{O}$ \\
\hline Meared & & & \\
\hline
\end{tabular}

${ }^{a}$ Measured from static contact angles. ${ }^{b}$ Calculated from Owens-Wendt's equation.

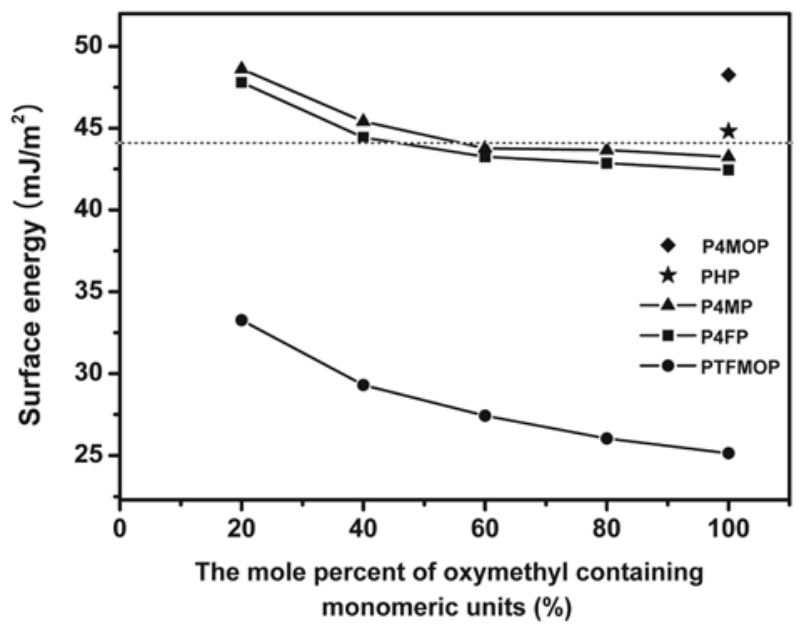

Figure 9. Surface energy of the polymers as a function of the mole percent of the side functional groups.

Those polymers having smaller surface energy values such as P4FP, P4MP, and PTFMOP show homeotropic LC alignment behavior. The smaller surface energy values for P4FP and PTFMOP could be ascribed to the fluorine groups in the polymer, as reported by others. ${ }^{40,57}$ The relatively small surface energy of P4MP compared with other non-fluorinated polymers could be ascribed to its side terminal $\mathrm{CH}_{3}$ groups. ${ }^{40}$ Although P4MOP also has side terminal $\mathrm{CH}_{3}$ groups, the surface energy of this polymer is relatively large, because the additional oxygen attached to the $\mathrm{CH}_{3}$ group increases the dipole interaction. We found that the unrubbed films having surface energy values of less than about $44 \mathrm{~mJ} / \mathrm{m}^{2}$ show homeotropic LC alignment, and this trend can be seen very clearly in Figure 9; the polymer films in the upper and lower parts of the dashed line show planar and homeotropic LC alignment behaviors. The surface energy values of the rubbed films were also measured in order to investigate the effect of the wettability on the pretilt angles of the LCs on rubbed surfaces as a function of the rubbing density. We found that the surface energy values on the rubbed polymer films were almost the same as those on the unrubbed polymer films. Therefore the changes of the pretilt angles and LC orientation after the rubbing process are not caused by the changes of the surface energies but by the changes of the molecular orientation on the polymer surfaces. The changes of the molecular orientation on the polymer surfaces caused by the rubbing process are confirmed by the FTIR dichroic spectra shown in Figure 7 as well as by the reports of many others. ${ }^{17,20,31-33}$

\section{Conclusions}

A series of polystyrene derivatives containing various phenoxymethyl side chain groups were synthesized by the reactions between polychloromethylstyrene with phenol, 4- 
fluorophenol, 4-methoxyphenol, 4-methylphenol, and 4-trifluoromethoxyphenol in order to investigate the effect of the phenoxymethyl terminal moieties in the side chain on their liquid crystal (LC) alignment properties. The LC cells made from the unrubbed films of 4-fluorophenoxymethyl-substituted polystyrene, 4-methylphenoxymethyl-substituted polystyrene, or 4-trifluoromethoxyphenoxymethyl-substituted polystyrene showed very uniform homeotropic LC alignment behavior. This could be ascribed to the incorporation of the fluoro, methyl, or trifluoromethoxy groups into the number 4 position of phenoxymethyl to produce polymer surfaces having low surface energy values of less than 44 $\mathrm{mJ} / \mathrm{m}^{2}$. When the LC cells were fabricated from the rubbed polymer films with a rubbing density of 100 using phenoxymethyl-substituted polystyrene or 4-fluorophenoxymethyl-substituted polystyrene, homogeneous planar and perpendicular LC alignment with respect to the rubbing direction was observed. This homogeneous planar and perpendicular LC alignment behavior was ascribed to the favorable anisotropic interactions between the LC molecules and the side groups that were preferentially oriented perpendicular with respect to the rubbing direction.

Acknowledgements. Financial supports by the Research Institute of Engineering \& Science (RIES) at Seoul National University, Korea Research Foundation through the Basic Research Program (grant No. KRF-2008-314-D00112), and Soongsil University are gratefully acknowledged.

\section{References}

(1) T. Kohki, H. Masaki, K. Mitsuhiro, I. Nobuyuki, H. Ray, and S. Masanori, Alignment Technologies and Applications of Liquid Crystal Devices, Taylor \& Francis, New York, 2005.

(2) K. Ichimura, Chem. Rev., 100, 1847 (2000).

(3) M. O’Neill and S. M. Kelly, J. Phys. D: Appl. Phys., 33, R67 (2000).

(4) M. Schadt, Annu. Rev. Mater. Sci., 27, 305 (1997).

(5) N. Almeria and R. Paul, Chem. Rev., 102, 4139 (2002).

(6) M. Ree, Macromol. Res., 14, 1 (2006).

(7) M. K. Ghosh and K. L. Mittal, Polyimides: Fundamentals and Applications, Marcel Dekker, New York, 1996.

(8) M. B. Feller, W. Chen, and T. R. Shen, Phys. Rev. A, 43, 6778 (1991).

(9) N. A. J. van Aerle and A. J. W. Tol, Macromolecules, 27, 6520 (1994).

(10) K.-W. Lee, S.-H. Paek, A. Lien, C. Durning, and H. Fukuro, Macromolecules, 29, 8894 (1996).

(11) K. Weiss, C. Woll, E. Hohm, B. Fiebranz, G. Forstmann, B. Peng, V. Scheumann, and D. Johannsmann, Macromolecules, 31, 1930 (1998).

(12) J. Stohr, M. G. Samant, A. Cossy-Favre, J. Diaz, Y. Momoi, S. Odahara, and T. Nagata, Macromolecules, 31, 1942 (1998).

(13) R. Meister and B. Jerome, Macromolecules, 32, 480 (1999).

(14) S. W. Lee, S. I. Kim, Y. H. Park, M. Ree, Y. N. Rim, H. J. Yoon, H. C. Kim, and Y.-B. Kim, Mol. Cryst. Liq. Cryst.,
349, 279 (2000).

(15) J. J. Ge, C. Y. Li, G. Xue, I. K. Mann, D. Zhang, S.-Y. Wang, F. W. Harris, S. Z. D. Cheng, S.-C. Hong, X. Zhuang, and Y. R. Shen, J. Am. Chem. Soc., 123, 5768 (2001).

(16) D. Kim, M. Oh-e, and Y. R. Shen, Macromolecules, 34, 9125 (2001).

(17) B. Chae, S. B. Kim, S. W. Lee, S. I. Kim, W. Choi, B. Lee, M. Ree, K. H. Lee, and J. C. Jung, Macromolecules, 35, 10119 (2002).

(18) S. W. Lee, B. Chae, B. Lee, W. Choi, S. B. Kim, S. I. Kim, S.-M. Park, J. C. Jung, K. H. Lee, and M. Ree, Chem. Mater. 15, 3105 (2003).

(19) S. J. Lee, J. C. Jung, S. W. Lee, and M. Ree, J. Polym. Sci. Part A: Polym. Chem., 42, 3130 (2004).

(20) S. G. Hahm, T. J. Lee, T. Chang, J. C. Jung, and W.-C. Zin, Macromolecules, 39, 5385 (2006).

(21) K. E. Vaughn, M. Sousa, D. Kang, and C. Rosenblatt, Appl. Phys. Lett., 90, 194102 (2007).

(22) S. I. Kim, M. Ree, T. J. Shin, and J. C. Jung, J. Polym. Sci. Part A: Polym. Chem., 37, 2909 (1999).

(23) Y. J. Lee, J. G. Choi, I.-K. Song, J. M. Oh, and M. H. Yi, Polymer, 47, 1555 (2006).

(24) W. Dong and S.-H. Paek, Macromol. Res., 12, 251 (2004).

(25) J. M. Geary, J. W. Goodby, A. R. Kmetz, and J. S. Patel, J. Appl. Phys., 62, 4100 (1987).

(26) S. Ishihara, H. Wakemoto, K. Nakazima, and Y. Mastuo, Liq. Cryst., 4, 669 (1989).

(27) D.-S. Seo, K.-I. Muroi, T.-R. Isogomi, H. Matsuda, and S. Kobayashi, Jpn. J. Appl. Phys., 31, 2165 (1992).

(28) D.-S. Seo, N. Yoshida, S. Kobayashi, M. Nishikawa, and Y. Yabe, Jpn. J. Appl. Phys., 34, 4876 (1995).

(29) A. D. Schwab, D. M. Agra, J.-H. Kim, S. Kumar, and A. Dhinojwala, Macromolecules, 33, 4903 (2000).

(30) M. Oh-e, S.-C. Hong, and Y. R. Shen, Appl. Phys. Lett., 80, 784 (2002).

(31) S. W. Lee, B. Chae, H. C. Kim, B. Lee, W. Choi, S. B. Kim, T. Chang, and M. Ree, Langmuir, 19, 8735 (2003).

(32) S. W. Lee, J. Yoon, H. C. Lee, B. Lee, T. Chang, and M. Ree, Macromolecules, 36, 9905 (2003).

(33) S. G. Hahm, T. J. Lee, S. W. Lee, J. Yoon, and M. Ree, Mater. Sci. Eng. B, 132, 54 (2006).

(34) H. Kang, K.-S. Kwon, D. Kang, and J.-C. Lee, Macromol. Chem. Phys., 208, 1853 (2007).

(35) H. Kang, D. Kang, and J.-C. Lee, Liq. Cryst., 35, 1005 (2008).

(36) H. Kang, J. S. Park, D. Kang, and J.-C. Lee, Macromol. Chem. Phys., 209, 1900 (2008).

(37) G. Odian, Principles of Polymerization, J. Wiley \& Sons, New York, 2004, Chapter 3.

(38) D. K. Owens and R. C. Wendt, J. Appl. Polym. Sci., 13, 1741 (1969).

(39) G. J. Sprokel, The Physics and Chemistry of Liquid Crystal Devices, Springer, New York, 1980.

(40) J. Brandrup, E. H. Immergut, and E. A. Grulke, Polymer Handbook, J. Wiley \& Sons, New York, 1999, Chapter 6.

(41) R. A. Hayes, J. Appl. Polym. Sci., 15, 318 (1961).

(42) B. Wesslin, R. W. Lenz, W. J. MacKnight, and F. E. Karaz, Macromolecules, 4, 24 (1971). 
(43) J.-C. Lee, M. H. Litt, and C. E. Rogers, J. Polym. Sci. Part B: Polym. Phys., 36, 75 (1998).

(44) D. W. Van Krevelen, Properties of Polymers, Elsevier, Amsterdam, 1990, Chapter 21.

(45) K. Sakamoto, R. Arafune, S. Ushioda, Y. Suzuki, and S. Morokawa, J. Appl. Phys., 80, 431 (1996).

(46) G. D. Hiepas, J. M. Sandas, and D. L. Allara, J. Phys. Chem. $B, \mathbf{1 0 2}, 10556$ (1998).

(47) D.-M. Shin, D.-M. Song, and Y.-B. Kim, Mater. Sci. Eng. C, 24, 127 (2004).

(48) S. W. Lee, B. Chae, S. G. Hahm, B. Lee, S. B. Kim, and M. Ree, Polymer, 45, 4068 (2005).

(49) B. S. Ban, Y. N. Rim, and Y. B. Kim, Liq. Cryst., 27, 125 (2000).

(50) M. Lu, Jpn. J. Appl. Phys., 43, 8156 (2004).
(51) J.-B. Lee, H.-K. Lee, J.-C. Park, and Y.-B. Kim, Mol. Cryst Liq. Cryst., 439, 161 (2005).

(52) S.-K. Oh, M. Nakagawa, and K. Ichimura, J. Mater. Chem., 11, 1563 (2001).

(53) Y. Matsuzawa and M. Matsumoto, Mol. Cryst. Liq. Cryst., 412, 181 (2004).

(54) H. J. Ahn, S. J. Rho, K. C. Kim, J. B. Kim, B. H. Hwang, C. J. Park, and H. K. Baik, Jpn. J. Appl. Phys., 44, 4092 (2005).

(55) A. D. Price and D. K. Schwartz, Langmuir, 22, 9753 (2006).

(56) Y. J. Lee, Y. W. Kim, J. D. Ha, J. M. Oh, and M. H. Yi, Polym. Adv. Technol., 18, 226 (2007).

(57) S. Turri, M. Scicchitano, R. Marchetti, A. Sanguineti, and S. Radice, Fluoropolymers: vol. 2 Properties, Plenum Publishers, New York, 1999. 